\title{
Prediksi Pengaruh Matakuliah Terhadap Peminatan Outline Tugas Akhir Mahasiswa Dengan Jaringan Syaraf Tiruan
}

\author{
Mugi Raharjo', Musriatun Napiah', Jordy Lasmana Putra ${ }^{3}$, Mustofa $^{4}$ \\ 1,2,3,4 Universitas Bina Sarana Informatika \\ e-mail: ${ }^{1}$ mugi.mou@bsi.ac.id, ${ }^{2} \underline{\text { musriatun.mph@bsi.ac.id, }}, \underline{3 \text { Jordy.jlp@bsi.ac.id, }}{ }^{4}$ mustofa.muo@bsi.ac.id

\begin{tabular}{ccc}
\hline Diterima & Direvisi & Disetujui \\
$28-03-2020$ & $05-05-2020$ & $20-05-2020$ \\
\hline
\end{tabular}

\begin{abstract}
Abstrak - Spesialisasi jurusan menjadi hal penting bagi sebuah perguruan tinggi, juga dalam pengambilan keputusan mahasiswa untuk menentukan penjurusan atau outline tugas akhir yang akan mereka pilih. Dalam penulisan ini kami membuat prediksi peminatan berdasarkan data nilai matakuliah terkait jurusan. Penulis menggunakan metode Jaringan Syaraf Tiruan (Artificial Neural Network) yang menghasilkan model seperti syaraf otak manusia berupa neuron dalam memecahkan masalah. Berdasarkan hasil pengumpulan data yang dilakukan serta melewati proses pemilihan data (Preproccessing), selanjutnya dilakukan pengolahan data menggunakan software rapidminer dan dibuatlah modelling untuk algoritma jaringan syaraf tiruan serta performa atau evaluasi dari hasil model yang di buat dan di dapatkan keluaran berupa data hasil uji yang menghasilkan output dan performa dengan tingkat akurasi sebesar 85,97\% dan nilai AUC sebesar 0,801. Diharapkan dengan adanya hasil penelitian ini dapat digunakan sebagai bahan evalusi terhadap perguruan tinggi, program studi dan himpunan program studi untuk bisa memanfaatkan hasil tersebut untuk menentukan focus pembelajaran terhadap mahasiswanya terkait peminatan dan dapat dikembangkan lagi dalam penelitian berikutnya.
\end{abstract}

Kata kunci: jaringan syaraf tiruan, proses, data

\begin{abstract}
Specialization majors in a university is very important. This specialization make students are expected to be able to focus on the areas of interest. On the other hand with the specialization of majors, it requires students to determine majors. The determination of this course is very important for students as a first step in preparing the final project. The large number of students makes it difficult for universities to provide detailed coaching. Then we need a system to simplify this problem. This paper will discuss about building a model to predict specialization based on student grades. This research uses the Artificial Neural Network method that produces models such as the human brain in the form of neurons in solving problems. The study was conducted by collecting data, sorting data (preporccessing). Then the data is processed using Rapidminer (modeling) software. From the modeling conducted, we found the results of the test data resulted in performance with an accuracy rate of $85.97 \%$ and AUC of 0.801. It is hoped that the results of this research can be used as an evaluation material for universities, study programs and study program associations to determine the focus of student learning.
\end{abstract}

Keywords: neural network, process, data

\section{PENDAHULUAN}

Pemanfaatan teknologi terhadap berbagai aspek kehidupan saat ini sangatlah dibutuhkan,tidak lain halnya dalam bidang pengumpulan dan pengolahan data. Dalam mengumpulkan atau mengolah data mungkin memang bisa dilakukan tanpa sebuah bantuan aplikasi atau teknologi canggih yang biasa kita gunakan sehari-hari , tetapi bagaimana jika data yang kita kumpulkan dan di olah adalah data yang jumlahnya cukup besar tentunya dalam hal tersebut kita membutuhkan bantuan dari tools dan memanfaatkan berbagai metode yang nantinya akan menghasilkan suatu kajian ilmiah gunanya untuk memperoleh hasil dari data yang diproses dan nantinya bisa digunakan untuk sebuah pengambilan keputusan, prediksi atau klasifikasi.
Dalam studi kasus ini, penulis menggunakan data institusi perguruan tinggi yang memiliki data kemahasiswaan berupadata kelulusan mahasiswa dalam sebuah mata kuliah, yang bisa dimanfaatkan untuk keperluan pengambilan keputusan. Dengan adanya pengolahan dan analisis data kelulusan mahasiswa, maka data tersebut menjadi sangat berarti bagi keperluan perguruan tinggi. (Rochman, 2019) Data mahasiswa yang lulus dapat memberikan informasi yang berguna bagi Perguruan Tinggi jika dimanfaatkan dengan maksimal. Salah satu cara untuk memanfaatkan data tentang mahasiswa yang lulus ini adalah dengan mengolahnya menggunakan data mining. Dengan proses data mining ini dapat ditemukan pola atau aturan yang dapat digunakan untuk menghasilkan suatu informasi seperti prediksi kelulusan mahasiswa (Siswanto, 2019) 
Prediksi merupakan proses peramalan suatu kejadian di masa yang akan datang dengan lebih mendasarkan pada pertimbangan subjektif atau intuisi daripada data kejadian pada masa lalu. Meskipun lebih menekankan pada intuisi, prediksi juga terdapat data kuantitatif yang dipakai sebagai masukan dalam melakukan peramalan. (Pada, Candi, \& Sidoarjo, 2018)

Dalam prosesnya analasi ini membutuhkan penyaringan data yang dilakukan yaitu proses data latih dan data uji. Pada penentuan arsitektur jaringan, data dibagi menjadi dua yaitu data pelatihan dan pengujian. Data pelatihan dan pengujian. Pembagian data tersebut berguna untuk agar jaringan mendapat data pelatihan yang secukupnya dan data pengujian dapat menguji prestasi pelatihan yang dilakukan berdasarkan nilai MSE data pelatihan dan MAPE pengujian. (Febrina, Arina, \& Ekawati, 2013)

Banyak neuron yang tersebar di seluruh bagiannya. Masing-masing neuron dikelompokkan ke dalam beberapa lapisan, antara lain: lapisan masukan, lapisan tersembunyi, dan lapisan keluaran (Coding et al., 2015)

Merupakan salah satu representasi buatan dari otak manusia yang selalu mencoba untuk mensimulasikan proses pembelajaran pada otak manusia tersebut. Istilah buatan disini digunakan karena jaringan syaraf ini diimplemintasikan dengan menggunakan program komputer yang mampu menyelesaikan sejumlah proses perhitungan selama proses pembelajaran.(Yanti, Cynthia, Vitriani, \& Azmi, 2019)

Sistem pemrosesan informasi yang didesain dengan meniru cara kerja otak manusia dalam menyelesaikan suatu masalah dengan melakukan proses belajar melalui perubahan bobot sinapsisnya. Ada banyak teknik yang dapat digunakan untuk implementasi Jaringan Syaraf Tiruan yaitu Perceptron, Backpropagation dan Fuzzy (Informatika et al., 2013)

Representasi buatan yang mencoba mensimulasikan proses pembelajaran pada otak manusia. Beberapa metode JST yang dapat digunakan untuk mengenali suatu citra atau pola adalah Backpropagation, Learning Vector Quantization (LVQ), dan Perceptron.(Sebagai \& Satu, 2016)

Dari penelitian di atas maka pemilihan matakuliah yang digunakan sebagai data untuk prediksi dipilih matakuliah yang sangat berhubungan dengan peminatan jurusan tersebut, untuk itu penulis menggunakan beberapa sample dari hasil pengumpulan data yang dikumpulkan. Tujuan dari penelitian ini adalah untuk memprediksi minat mahasiswa terhadap pemilihan outline melalui data yang Penulis ambil dari penilaian di sebuah kelas laboratorium Praktikum Jaringan Komputer.kemudian Penulis menggunakan survey metode untuk mendata minat mahasiswa dari beberapa kelas yang dijadikan sample, Selanjutnya
Penulis menerapkan metode Artificial Neural Network untuk memprediksi serta meningkatkan keakuratan pada prediksi terhadap peminatan Mahasiswa berdasarkan matakuliah yang sangat berkaitan dengan penjurusan tersebut.

\section{Metode Penelitian}

Penelitian ini mengacu kepada studi literatur atau kepustakaan yang dilakukan dengan menelusuri literatur serta menelaahnya untuk mencari penelitian-penelitian yang sedang berkembang, mencari metode penelitian yang sudah digunakan terdahulu untuk memperoleh orientasi yang ada dalam permasalahan. Selanjutnya adalah pemilihan obyek penelitian yang dilakukan untuk mengprediksi peminatan terhadap peminatan outline acuan matakuliah Praktikum Jaringan Komputer.Obyek penelitian ini sengaja dipilih dengan pertimbangan jumlah peminat terhadap penjurusan perlu di analisa sebagai bahan acuan untuk mengembakan matakuliah-matakuliah yang berkaitan dengan peminatan outline.

Tahap berikutnya dalam penelitian ini adalah menganalisis Algoritma yang akan digunakan dalam klasifikasi mahasiswa, menelaah berbagai metode yang bisa digunakan agar tingkat akurasi yang diperoleh nantinya bisa maksimal.Dalam hal ini peneliti menggunakan jaringan syaraf tiruan (Neural Network).

Preprocessing adalah tahap data mahasiswa yang diproses untuk dipilih menyesuaikan kebutuhan pemodelan. Berikutnya data tersebut ditransformasi dan reduksi. Pada proses transformasi, data ditransformasikan dalam bentuk yang sesuai untuk proses data mining. Selanjutnya data direduksi yaitu dengan melakukan penghilangan atribut yang tidak diperlukan sehingga ukuran dari database menjadi kecil dan hanya menyertakan atribut yang diperlukan dalam proses data mining.(Raharjo, Putra, Alfian, \& Sandi, 2019)

Prediksi yang akurat dapat dilakukan dengan mengenal pola dari beberapa parameter dari air sungai, seperti kekeruhan air, temperatur air, dan $p H$ air dari waktu ke waktu. Jaringan Saraf Tiuran (JST) adalah sebuah sistem yang meniru cara kerja otak manusia, dan memberi hasil yang sangat bagus untuk pengenalan pola. Namun implementasi JST tidak sederhana, dalam kasus Jurnal ini, masalah pertama yang muncul adalah akuisisi data kondisi air sungai (suhu, kekeruhan, dan $p H$ ). Setelah akuisisi data, muncul masalah mengenai implementasi JST, yakni dalam perancangan dan pelatihan. Terakhir, terdapat tantangan untuk melakukan klasifikasi tingkat pencemaran air sungai. Jurnal ini berpusat pada masalah implementasi JST, mengenai arsitektur dan metode pelatihan yang optimal.(Elektro, Telkom, \& Air, 2019) 
Jaringan syaraf tiruan (JST) adalah paradigma pemrosesan suatu informasi yang terinspirasi oleh sistem sel syaraf biologi. JST dibentuk sebagai generalisasi model matematika dari jaringan syaraf biologi, dengan asumsi bahwa:

1. Pemrosesan informasi terjadi pada banyak elemen sederhana (neuron).

2. Sinyal dikirimkan diantara neuron-neuron melalui penghubung-penghubung.

3. Penghubung antar neuron memiliki bobot yang akan memperkuat atau memperlemah sinyal.

4. Untuk menentukan output, setiap neuron mengg unakan fungsi aktivasi (biasanya bukan fungsi linier) yang dikenakan pada jumlahan input yang diterima. Besarnya output ini selanjutnya dibandingkan dengan suatu batas ambang.

Berikut alur atau kerangka kerja penelitian yang digunakan untuk menyelesaikan penelitian ini dapat dilihat pada gambar .

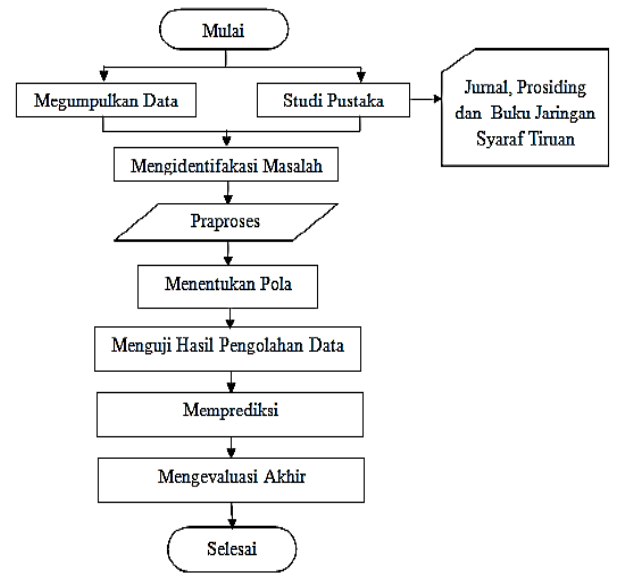

Gambar1. Flow Chart

Dari gambar kerangka kerja diatas maka masingmasing langkah dapat di uraikan sebagai berikut :

1. Pengumpulan Data

Pada tahap ini data yang dikumpulkan adalah beberapa sampel data dari kelas-kelas matakuliah yang dijadikan data.

2. Studi Pustaka

Tahap ini merupakan tahap dimana sebuah penelitian harus melihat atau merujuk dalam langkah awal dalam penelitianuntuk melengkapi pengetahuan dasar beserta teori-teori dalam penelitian ini.

3. Mengidentifikasi Masalah

Pada tahap indentifikasi masalah ini, setelah semua data terpenuhi dan diperoleh data yang sangat akurat untuk melakukan konversi data sesuai dengan bobot yang telah ditentukan.

4. Praproses

Pada tahap ini yang dikerjakan ialah merubah tipe data dan atribut data yang bertujuan untuk mempermudah dalam pemahaman isi record data, dan melakukan seleksi data dengan memperhatikan kekonsistenan data .

5. Menentukan Model

Hasil pada tahap ini beberapa model bagian jaringan Saraf tiruan dengan metode Resilient untuk menentukan sebuah pola.

6. Menguji Hasil Pengolahan Data

Dalam pengujian hasil pengolahan data digunakan sebuah software Rapid Miner

7. Pemperediksi

Prediksi dilakukan berdasarkan model arsitektur terbaik.

8. Mengevaluasi Hasil Akhir

Evalusi hasil akhir ini untuk melihat dan mengetahui hasil akhir dari testing pengolahan data.

(Sinaga, Wanto, \& Solikhun, 2019)

Jaringan syaraf tiruan memiliki banyak neuron yang tersebar di seluruh bagiannya. Masing-masing neuron dikelompokkan ke dalam beberapa lapisan, antara lain: lapisan masukan, lapisan tersembunyi, dan lapisan keluaran. (Coding et al., 2015)

Dalam jaringan syaraf tiruan, aktivasi digunakan untuk menentukan keluaran suatu Neuron. Argument fungsi aktivasi adalah net masukan (kombinasi linier masukan dan bobotnya). Beberapa fungsi aktivasi yang digunakan adalahFungsi Threshold (batas ambang). Fungsi Threshold merupakan fungsi threshold biner. Untuk kasus bilangan bipolar, maka angka 0 diganti dengan angka - 1 . Adakalanya dalam jaringan syaraf tiruan ditambahkan suatu unit masukkan yang nilainya selalu 1 . Unit tersebut dikenal dengan bias. Bias dapat dipandang sebagai sebuah input yang nilainya selalu 1 . Bias berfungsi untuk mengubah threshold menjadi $=0$.

\section{HASIL DAN PEMBAHASAN}

Data yang penulis gunakan adalah menggunakan data dari penilaian mahasiswa selama satu semester.Data awal yang dimiliki dilakukan normalisasi dengan metode minmax.

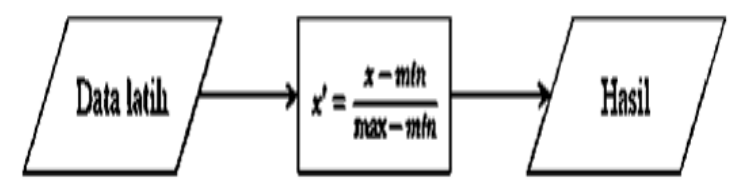

Gambar 1. rumus minmax

Keterangan :

$\mathrm{x}=$ data yang akan dinormalisasi

$\min =$ data minimal

$\max =$ data maksimal 
Berikut adalah data awal sebelum dilakukan normalisasi , data tersebut adalah berupa data inputan yang akan digunakan sebanyak 6 (enam) inputan.Dalam table tersbut terdapat unsur-unsur dalam matakuliah diantaranya adalah absen, tugas , uts , uas , totoal nilai dan $\mathrm{Y}=$ keputusan Lulus atau tidak lulus nantinya data ini akan di normalisasi sehingga variable yang akan digunakan nanti dapat menghasilkan tingkat akurasi yang jauh lebih baik dari penelitaian-penelitian sebelumnya.

Tabel 1. Dataset awal

\begin{tabular}{llllll}
\hline $\mathbf{X 1}$ & $\mathbf{X 2}$ & $\mathbf{X 3}$ & $\mathbf{X 4}$ & $\mathbf{X 5}$ & $\mathbf{Y}$ \\
\hline $\mathbf{2 0}$ & 8 & 24 & 27 & 79 & 1 \\
\hline $\mathbf{2 0}$ & 20 & 24 & 30 & 94 & 1 \\
\hline $\mathbf{8}$ & 10 & 15 & 0 & 33 & 0 \\
\hline $\mathbf{2 0}$ & 20 & 24 & 30 & 94 & 1 \\
\hline $\mathbf{2 0}$ & 20 & 24 & 30 & 94 & 1 \\
\hline $\mathbf{2 0}$ & 20 & 24 & 30 & 94 & 1 \\
\hline $\mathbf{8}$ & 10 & 15 & 0 & 33 & 0 \\
\hline $\mathbf{2 0}$ & 8 & 24 & 27 & 79 & 1 \\
\hline
\end{tabular}

Tahap preprocessing atau normalisasi data dilakukan dengan rumus minmax tadi dan menghasilkan nilai sesudah dilakukan normalisasi, table input seperti berikut. Data PreparationData yang ada akan dilakan pembersihan dengan cara membuang data yang duplikat, data yang kosong dan melakukan seleksi terhadap atribut yang tidak berpengarus terhadapat hasil analisa,

Tabel 2. Data preprocessing

\begin{tabular}{llllll}
\hline $\mathbf{x 1}$ & $\mathbf{x 2}$ & $\mathbf{x 3}$ & $\mathbf{x 4}$ & $\mathbf{x 5}$ & $\mathbf{y}$ \\
\hline $\mathbf{1 8 . 9 5}$ & -0.4 & 17.8 & 14.6 & 76 & 1 \\
\hline $\mathbf{1 8 . 9 5}$ & 11.6 & 17.8 & 17.6 & 91 & 1 \\
\hline $\mathbf{6 . 9 5}$ & 1.6 & 8.8 & -12.4 & 30 & 0 \\
\hline $\mathbf{1 8 . 9 5}$ & 11.6 & 17.8 & 17.6 & 91 & 1 \\
\hline $\mathbf{1 8 . 9 5}$ & 11.6 & 17.8 & 17.6 & 91 & 1 \\
\hline
\end{tabular}

Dalam proses selanjutnya menggunakan metode jaringan syaraf tiruan (Artificial Neural Network) dengann tools Rapid Miner.

Data yang digunakan adalah hasil dari nilai mahasiswa yang telah dikumpulkan dan dilakukan preprocessing data sebanyak 200 data mahasiswa, yang nantinya akan kita lakukan pengolahan data untuk memprediksi menggunakan metode NN (neural network) dan akan menghasilkan model neural network serta tingkat akurasi yang didapatkan dari pengujian metode ini. Penulis juga melakukan survey terhadap minat mahasiswa melalu form online dan di gunakan sebagai Label pada dataset yang di gunakan.

Tahap pertama penulis menggunakan RapidMiner untuk toolsnya , selanjutnya menginput file data excel ke tool read excel dan melakukan pemilihan attribute.Setelah itu melakukan missing value apabila ada data yang empty atau kosong atau bernilai 0 untuk dihapus.

Kemudian menyeleksi attribute yang akan digunakan dan melakukan validasi terhadap data.

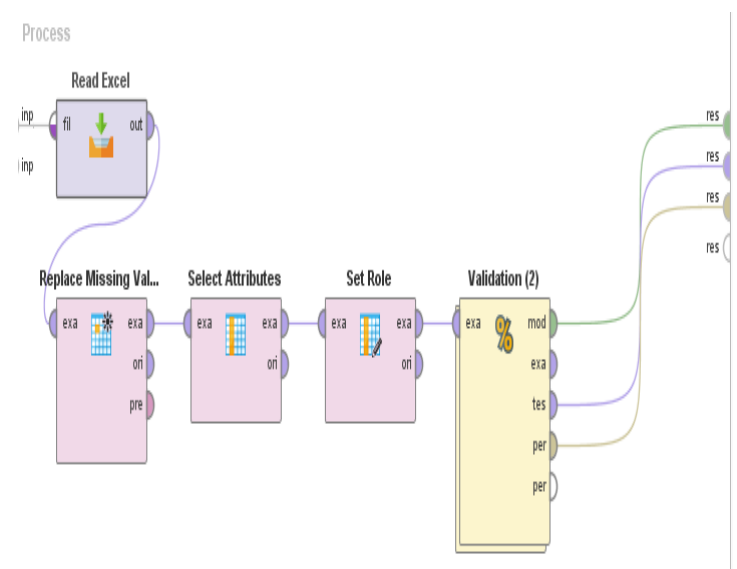

Gambar 2. Processing data dengan Mesin

Pada tahap processing data menggunakan mesin ini dilakukan tahap pemilihan data yang diperlukan ,pemilihan attribute dan label pada data berupa excel yang selanjutnya di proses dengan pemilihan special attribute untuk meningkatkan akurasi.

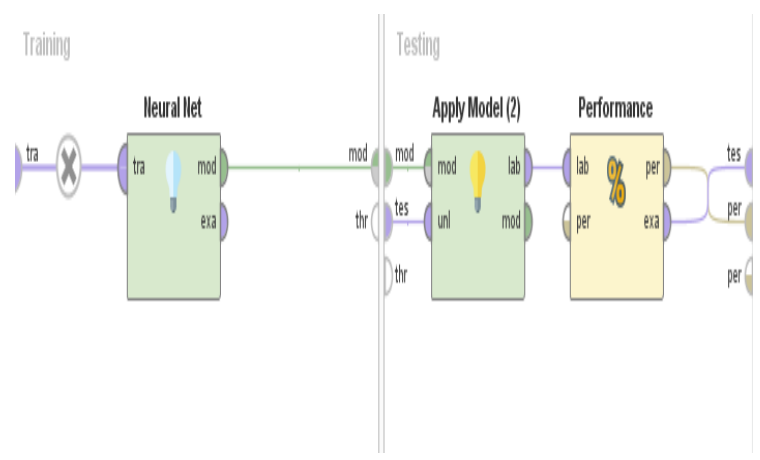

Gambar 3. Training dan testing

Tahap validasi dilakukan dengan dua kali tahap yaitu training dan testing dimana kita memasukkan metode atau tools yang akan digunakan, disini kita gunakan $\mathrm{NN}$ (neural network) dan masuk ke testing untuk di gunakan modelnya dan melakukan cek performance agar diketahui hasil akurasi dan nilai AUC. 


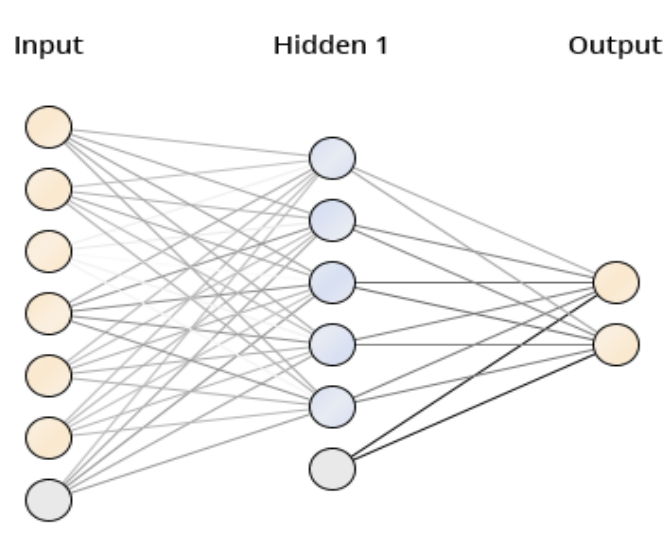

Gambar 4. Model Neural Network

Jaringan syaraf tiruan mempunyai sebuah model atau arsitektur. Arsitektur neural network tersebut tersusun dari beberapa layer yaitu input layer, hidden layer dan output layer. Pada gambar diatas menunjukan arsitektur neuron atau node (6-5-2) dengan menggunakan 5 hidden layer. Sistem yang akan menggunakan satu sampai delapan hidden layer dikarenakan akan mencari hasil keluaran output yang optimal dan dibatasi sampai delapan hidden karena semakin banyak hidden layer yang digunakan semakin berat pemrosesan pada computer.

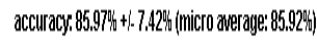

\begin{tabular}{|l|l|l|l|}
\hline & true 1 & true 0 & class precision \\
\hline pred. 1 & 164 & 29 & $84.97 \%$ \\
\hline pred. 0 & 1 & 19 & $95.00 \%$ \\
\hline llass recall & $99.39 \%$ & $39.58 \%$ & \\
\hline
\end{tabular}

Gambar 5. Nilai Akurasi

Accuracy $=\frac{(t p+t n)}{(t p+t n+f p+f n)} \times 100 \%$

Pengujian akurasi dilakukan dengan membuat beberapa skenario uji yaitu dengan

merubah nilai-nilai parameter learning rate (dimulai dari 0,1 hingga 0,9 ) dan pembagian data latih dan data uji.Pada tahap testing akhir dihasilkan tingkat akurasi dalam prediksi sebesar $85,97 \%$ termasuk akurasi yang tinggi dalam sebuah prediksi. Penulis melakukan pengujian berulang-ulang sampai menemukan formula yang tepat dalam hasil akurasi dengan menggunakan Jaringan syaraf tiruan

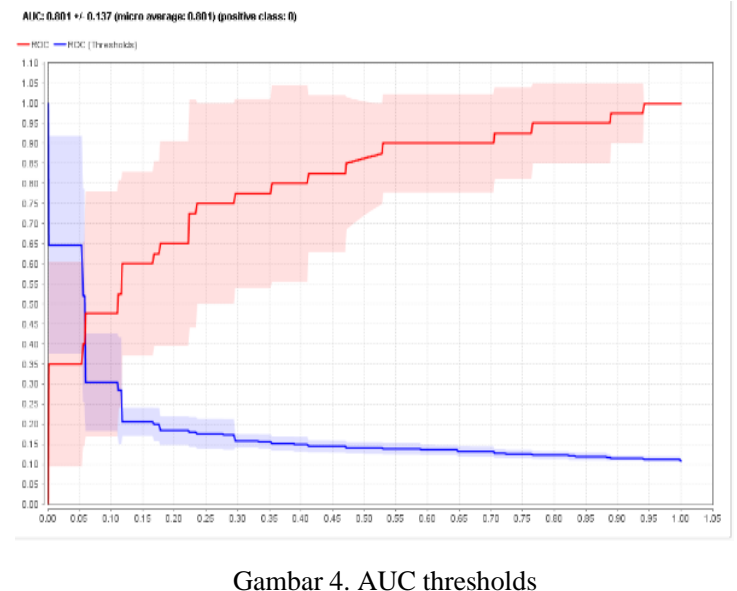

Pada gambar diatas kita bicara tentang AUC (Area Under the Curve). AUC membuat kita mudah dalam membandingkan model satu dengan yang lainnya. AUC adalah luas area di bawah curve ROC, atau integral dari fungsi ROC . ROC graph dari sampel kita dengan model logistic regression memiliki AUC $=0.801$ dan itu cukup baik dalam threshold suatu model.

\section{KESIMPULAN}

Metode JST dapat memberikan nilai prediksi, persentase error dan nilai error ratarata.Dari hasil yang telah dilakukan dalam penelitian ini, menunjukkan hasil yang lebih baik yaitu dengan nilai akurasi $=85,97 \%$ dan nilai $\mathrm{AUC}=0,801$. Penelitian ini menggunakan klasifikasi machine learning Neural Network yang menggunakan tools Rapid Miner 9.1 dengan training sebanyak 200, learning rate $=0,4$ dan momentum $=0,4$ dimana itu adalah rate dan momentum terbaik untuk mengjasilkan tingkat akurasi yang tinggi dengan demikian penelitian ini dapat dijadikan sebagai tolak ukur dalam menentukan tingkat keberhasilan peminatan terhadap outline tugas akhir mahasiswa untuk digunakan sebagai bahan penelitian selanjutnya untuk dikembangkan sebagai bahan evaluasi kampus dalam menerapkan kurikulum pembelajaran.

\section{REFERENSI}

Coding, J., Untan, S. K., Trimulya, A., Setyaningsih, F. A., Komputer, J. S., Elektro, J. T., ... Tanjungpura, U. (2015). Implementasi jaringan syaraf tiruan metode backpropagation untuk memprediksi harga saham 1,3, 3(2), 66-75.

Elektro, F. T., Telkom, U., \& Air, P. (2019). PREDIKSI POLA PENCEMARAN AIR SUNGAI MENGGUNAKAN SIMPLE NEURAL NETWORK RIVER WATER POLLUTION PATTERN PREDICTION USING A SIMPLE NEURAL, 6(1), 1590- 
1595.

Febrina, M., Arina, F., \& Ekawati, R. (2013). Peramalan Jumlah Permintaan Produksi Menggunakan Metode Jaringan Syaraf Tiruan ( JST ) Backpropagation, 1(2), 174-179.

Informatika, P., Darma, B., Matondang, Z. A., Backpropagation, A., Tiruan, S., Mengukur, U., ... Penentuan, U. (2013). Jaringan syaraf tiruan dengan algoritma backpropagation untuk penentuan kelulusan sidang skripsi, 84-93.

Mahasiswa, K. (2019). Jurnal Neo Teknika, Vol.5 No.1 Juni 2019 KOMPORASI METODE KLASIFIKASI DATA MINING UNTUK PREDIKSI KELULUSAN MAHASISWA, $5(1)$.

Pada, B., Candi, P. G., \& Sidoarjo, B. (2018). Peramalan Produksi Gula Menggunakan Metode Jaringan Syaraf Tiruan Peramalan Produksi Gula Menggunakan Metode Jaringan Syaraf Tiruan Backpropagation Pada PG Candi Baru Sidoarjo, (April).

Raharjo, M., Putra, J. L., Alfian, T., \& Sandi, A. (2019). Implementasi Metode Decision Tree Klasifikasi Data Mining Untuk Prediksi Peminatan Jurusan Robotika oleh Mahasiswa, $V(2)$. https://doi.org/10.31294/jtk.v4i2

Sebagai, D., \& Satu, S. (2016). Khairil Fitryadi JURUSAN ILMU KOMPUTER / INFORMATIKA.

Sinaga, S. P., Wanto, A., \& Solikhun, S. (2019). Implementasi Jaringan Syaraf Tiruan Resilient Backpropagation dalam Memprediksi Angka Harapan Hidup Masyarakat Sumatera Utara, 4(2).

Siswanto, E. (2019). Optimasi Metode Naïve Bayes Dalam Memprediksi Tingkat Kelulusan Mahasiswa Stekom Semarang, 6(1), 1-6.

Yanti, N., Cynthia, E. P., Vitriani, Y., \& Azmi, G. (2019). Prediksi Radiasi Matahari Dengan Penerapan Metode Elman Recurrent Neural Network, (November), 22-29. 